\title{
Compensation of top horizontal displacements of a riser
}

\author{
Iwona Adamiec-Wójcik • Jan Awrejcewicz • \\ Lukasz Drąg · Stanisław Wojciech
}

Received: 9 November 2015/Accepted: 4 May 2016/Published online: 15 August 2016

(C) The Author(s) 2016. This article is published with open access at Springerlink.com

\begin{abstract}
The nonlinear dynamic problem of catenary risers is solved by means of the rigid finite element method. The method enables us to model slender systems such as lines, cables and risers undergoing large base motions. The formulation allows elimination of large values of stiffness coefficients: shear, longitudinal and torsional (dependent on permissibility of the system analyzed). The analysis presented in the paper is concerned with the dynamics of a riser initially bent and undergoing heave excitation. Comparison of the results with those obtained using the finite difference and finite element methods shows good compatibility and indicates the correctness of the models obtained by means of the rigid finite element method. Numerical effectiveness of the method enables it to be applied in solving the dynamic optimization problem. The problem described is the compensation of the horizontal vibrations of the vessel or a platform by vertical displacements of the upper end of the riser. Bending moments which arise during the motion of a
\end{abstract}

I. Adamiec-Wójcik $(\bowtie) \cdot$ Ł. Drąg · S. Wojciech

University of Bielsko-Biala, Willowa 2,

43-309 Bielsko-Biała, Poland

e-mail: i.adamiec@ath.bielsko.pl

J. Awrejcewicz

Lodz University of Technology, Stefanowskiego 1/15,

90-924 Łódź, Poland platform or a vessel can seriously influence and in some cases damage the structure. Thus the aim of the optimization is to ensure that the maximum bending moment at a given point does not exceed its static counterpart. The results of numerical simulations show that the systems enabling heave compensation can be used to minimize the difference between the bending moment caused by displacements of the platform or a vessel and the static moment.

Keywords Slender systems ·

Longitudinal flexibility · Bending flexibility ·

Compensations of vibrations - Optimisation ·

Bending moment $\cdot$ Rigid finite element method

\section{Introduction}

Considerable deformation and change of shape is one of the inherent features of slender structures such as lines, cables and risers. Much research has been carried out into both linear and nonlinear dynamics of such systems. Benedettini et al. [1,2] intensively studied linear and nonlinear vibrations of cables and devoted their attention especially to the problem of coupling "in-plane" and "out-of plane" vibrations. Two further papers [3, 4] present the experimental set-up which enables such coupling to be investigated for a cable with eight lumped masses. Results of experimental measurements are compared with those of numerical simulations. Moreover, the authors 
assumed that nonlinear vibrations can be induced by motion of the supports.

Slender systems undergoing large base motion occur in offshore engineering systems where there is a coupling between the dynamics of a vessel or platform and attached risers or mooring lines and cables. In such cases not only bending and longitudinal flexibilities of slender systems but also large deflections have to be considered. Moreover, in the marine environment uplift pressure, drag force, added mass water and, in the case of risers, internal flow of hydrocarbons (petroleum and gas) has to be taken into account. An extensive discussion on the state of the art in modeling and on problems in total dynamic analysis of offshore systems is presented by Chakrabarti [5]. Although Patel and Seyed [6] report many different modelling methods, the most popular methods used are the lumped mass [7,8] and the finite element methods [9-11]. Those methods are used in commercial packages not only specialized in offshore engineering (Riffex, Orcaflex or Offpipe) but also of general use such as Abaqus. The Flexible Segment Model (FSM) presented in [12] is another similar approach. Nevertheless, new methods of modeling slender systems used in offshore engineering are still being sought [13-15], and this paper follows this trend by presenting a modified formulation of the rigid finite element method (RFEM).

The RFEM has been successfully used for dynamic analysis of flexible systems containing beam-like links [16, 17] or plates and shells $[18,19]$. Considerations of both bending and longitudinal flexibilities of slender links are presented in [20]. This paper presents the model which is derived using a modified formulation of RFEM in absolute coordinates [20,21]; this model is supplemented with relations describing the influence of hydrodynamic forces. The validation of the method concerned with: deflections of a catenary line; vibrations with large amplitudes of a line several hundred meters long; frequencies of free vibrations of a vertical riser additionally loaded with tension; vibrations of a vertical riser with the upper end moving periodically, is presented in [21]. The comparisons indicate the correctness of the models obtained by means of the rigid finite element method even when the influence of the water environment (drag forces, hydrodynamic resistance or added mass and currents) is considered.
This paper is concerned with dynamics of risers, especially vibrations due to which there is a significant increase in bending moments. First, the results are compared with those presented by Chatjigeorgiu [22] obtained by means of the finite element and finite difference methods. Numerical simulations show that acceptable exactness of the results is obtained even when the riser is divided into less than a hundred elements, so due to the numerical effectiveness of the method it is possible to use it in order to solve a dynamic optimization task. The aim of the optimization is such a choice of vertical displacement of the upper end of the riser attached to a vessel or platform that despite its horizontal displacements the magnitude of the bending moment in the riser does not exceed its static counterpart. The solution of the optimization problem requires integration of the nonlinear equations of motion at each optimization step. The solution consists of the parameters defining the function describing the motion of the upper end of the riser. The results can be used when at a certain point of the riser the bending moment has to be restricted to a certain value, for example when there is a risk of failure.

\section{Model of a riser}

The Rigid Finite Element Method (RFEM) is used in order to formulate the model of a riser. Detailed description of the modified formulation of RFEM used for modelling is presented in [21]. A flexible link is divided into rigid elements (rfe) reflecting mass features of the link connected by means of dimensionless spring-damping elements (sde) reflecting bending $\otimes$ and longitudinal $\otimes$ flexibilities (Fig. 1). The vector of generalized coordinates takes the following form:

$\mathbf{q}_{i}=\left[\begin{array}{llll}x_{i} & y_{i} & \Delta_{i} & \varphi_{i}\end{array}\right]^{T}$

where $x_{i}, y_{i}$ are coordinates of point $A_{i}, \Delta_{i}$ is the elongation of sde $\boldsymbol{\otimes}, \varphi_{i}$ is the declination angle of rfe $i$ towards the axis $\mathrm{x}$ of the global coordinate system.

In the paper the hydrodynamic forces are taken into account according to Morison's law. This approach is appropriate for nonlinear analysis presented in this paper, although more complicated fluid- 
Fig. 1 System of rigid finite and spring-damping elements

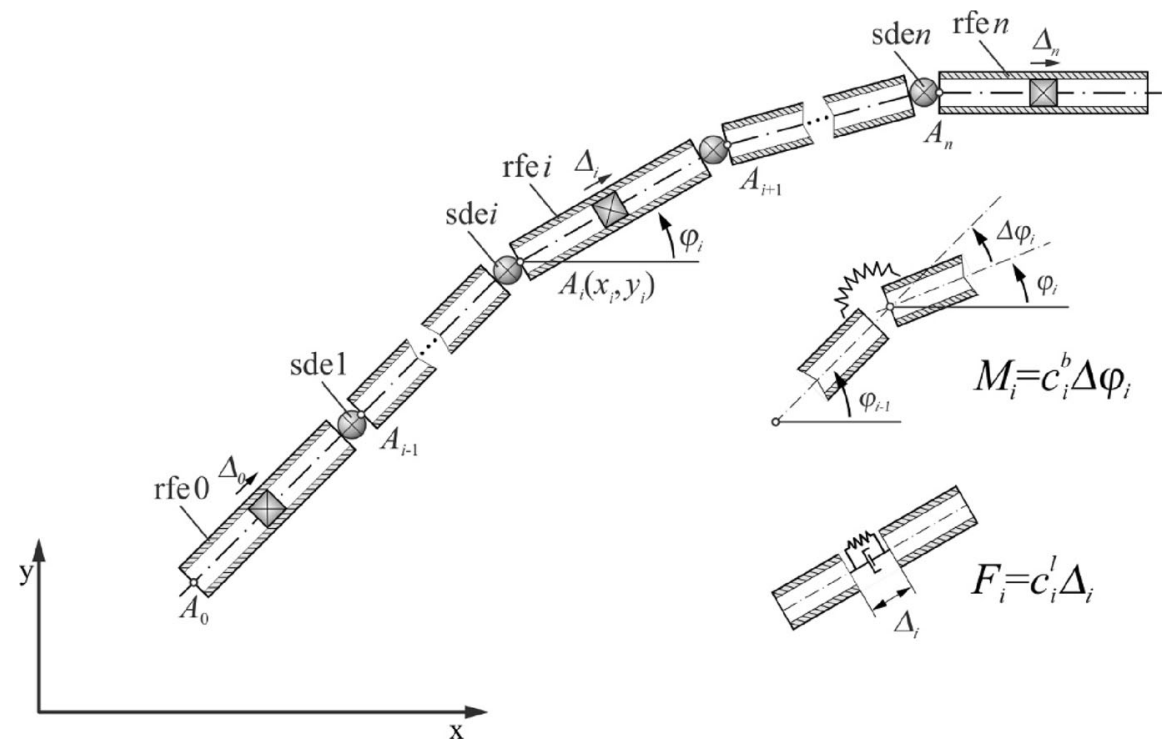

structure interaction can be also considered [23]. Having omitted the detailed derivations [21], the equations of motion describing the dynamics of the system can be written in the form

$\mathbf{M} \ddot{\mathbf{q}}-\mathbf{D R}=\mathbf{F}$

$\mathbf{D}^{T} \ddot{\mathbf{q}}=\mathbf{G}$

where $\mathbf{q}=\left[\begin{array}{llll}\mathbf{q}_{0}^{T} & \mathbf{q}_{1}^{T} & \ldots & \mathbf{q}_{n}^{T}\end{array}\right]^{T}$ is the vector of generalized coordinates of the system with $4(n+1)$ elements, $\mathbf{R}=\left[\begin{array}{llll}\mathbf{R}_{0}^{T} & \mathbf{R}_{1}^{T} & \ldots & \mathbf{R}_{n}^{T}\end{array}\right]^{T}$ is the vector of constraint reactions with $2(n+1)$ elements, $\mathbf{M}=$ $\mathbf{M}(\mathbf{q})=\operatorname{diag}\left(\begin{array}{llllll}\mathbf{M}_{0} & \mathbf{M}_{1} & \ldots & \mathbf{M}_{i} & \ldots & \mathbf{M}_{n}\end{array}\right) \quad$ is the mass matrix with variable elements together with the mass of added water, and $\mathbf{D}=\mathbf{D}(\mathbf{q})$, $\mathbf{F}=\mathbf{F}(t, \mathbf{q}, \dot{\mathbf{q}}), \mathbf{G}=\mathbf{G}(t, \mathbf{q}, \dot{\mathbf{q}})$, and $x_{A}(t), y_{A}(t)$ are known functions defining the motion of point $A_{0}$.

Equations (2) and (3) are nonlinear due to large deflections and nonlinear terms when forces caused by the water environment are considered.

Since matrix $\mathbf{M}$ has a block diagonal form, it is easy to calculate the inverse matrix $\mathbf{M}^{-1}$. The following can be obtained from (2)

$\ddot{\mathbf{q}}=\mathbf{M}^{-1}(\mathbf{F}+\mathbf{D R})=\mathbf{f}(t, \mathbf{q})$

where $\mathbf{M}$ is calculated by solving the system of linear algebraic equations:

$$
\left(\mathbf{D}^{T} \mathbf{M}^{-1} \mathbf{D}\right) \mathbf{R}=\mathbf{G}-\mathbf{D}^{T} \mathbf{M}^{-1} \mathbf{F}
$$

\section{Numerical simulations}

Dynamics of a catenary riser (Fig. 2) are analysed in [22] by means of the finite difference method. Three

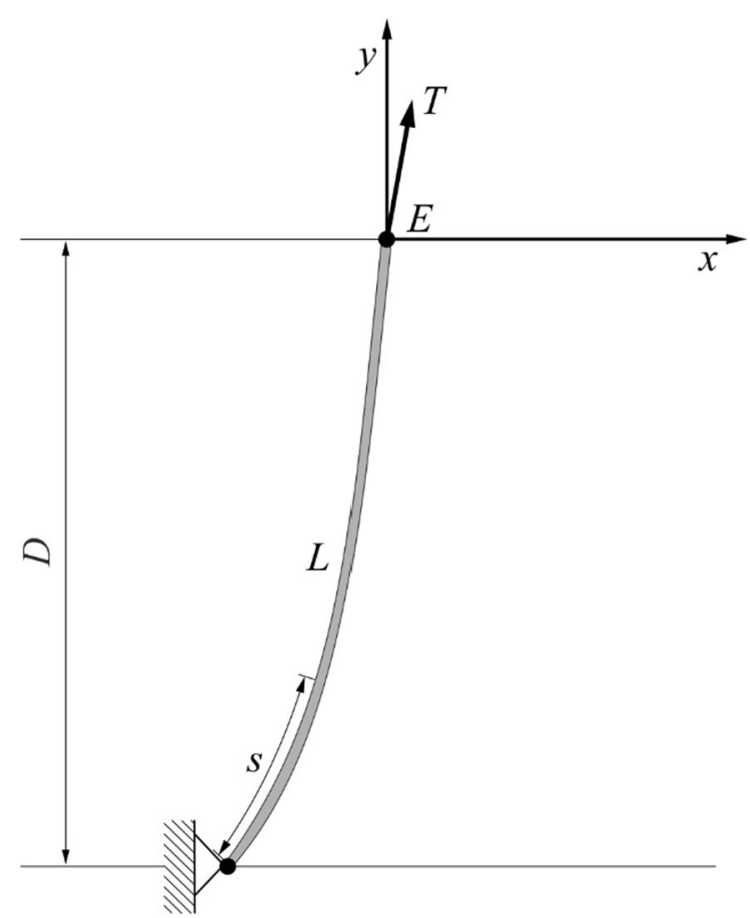

Fig. 2 Catenary riser 
models of risers with different lengths are considered in order to investigate the influence of heave motion on bending moments and tension or shear forces.

Axial excitations can have a considerable influence on dynamic behaviour of risers and catenary moorings and are especially important in practical applications. For the purpose of comparative analysis presented in this section only one of the models is used. The parameters of the analysed model of the riser are presented in Table 1.

Two types of harmonic motion are analysed:

W1-vertical motion with period $60 \mathrm{~s}$ and amplitude $5 \mathrm{~m}$.

W2-vertical motion with period $12 \mathrm{~s}$ and amplitude $2 \mathrm{~m}$.

It is assumed that horizontal motion of a vessel or platform is described by the following function:

$x_{E}=-a+a \cos \omega t$

where $a$ is the amplitude of motion, $\omega=2 \pi / T, T$ is the period of the harmonic motion.

Comparison of maximal and minimal values of bending moments as well as tension at the top of the riser and static top tension are presented in Table 2 . The results obtained with the rigid finite element $\mathrm{m}$ method (RFEM) are compared with those presented in [22] obtained using RIFLEX (RF) and the finite difference method (FD).

The results obtained using the rigid finite element method for $n=101$ elements are very close to those obtained with a nonlinear model (FD). More discrepancies can be seen when the results by the RFEM are compared with those from the linear model (RF -by commercial package RIFLEX). Figure $3 \mathrm{a}$ shows the static configuration of the riser and static bending moment obtained using the authors' model and those presented by [22]. It is important to note that the rigid finite element method takes into account rotational inertia of the elements and this explains the differences in maximal values of bending moments presented in Table 2. Consideration of rotational inertia results in larger hydraulic damping. Courses of the tension and shear forces, and of the bending moment along the riser are presented in Fig. $3 b-d$.

The rigid finite element method enables us to calculate displacements, inclination angles of the elements and forces at discrete points. Values at intermediate points (for an arbitrary $s$ ) can be calculated by means of spline functions. Figure 4 shows the influence of the number of elements $n$ into which the riser is divided on the results of the bending moment calculated at selected points for harmonic motion W2.

It can be seen that even for $n=40$ the results are acceptable. The simulation time for one instance of simulations does not exceed $5 \mathrm{~s}$ on a medium class personal computer.

\section{Optimisation}

Numerical effectiveness of the method enables it to be used in solving dynamic optimisation problems $[24,25]$. In the papers the method is used for modelling ropes in order to solve the problem of stabilisation of a load at a given depth despite vertical and horizontal movements of the base vessel.

Table 1 Parameters of the catenary riser

\begin{tabular}{lllll}
\hline & Parameter & Denotation & Value & Unit \\
\hline Riser & Suspended length & $L$ & 2022 & $\mathrm{~m}$ \\
& Outer diameter & $d_{\text {iout }}$ & 0.429 & $\mathrm{~m}$ \\
& Inner diameter & $d_{\text {in }}$ & $\mathrm{m}$ & $\mathrm{m}$ \\
& Young modulus & $\mathrm{E}$ & $2.07 \times 10^{11}$ & $\mathrm{~N} / \mathrm{m}^{2}$ \\
& Mass density & $\rho_{r}$ & 7758 & $\mathrm{~kg} / \mathrm{m}^{3}$ \\
Water & Mass density & $\rho_{w}$ & 1025 & 2 \\
& Added mass coefficient & $C_{M}$ & 2 & \\
& Normal drag coefficient & $C_{n}$ & 1 & \\
Fluid inside riser & Tangential drag coefficient & $C_{t}$ & 0 & $\mathrm{~kg} / \mathrm{m}^{3}$ \\
\hline
\end{tabular}


Table 2 Comparison of results obtained by RFEM and those presented in [22]

\begin{tabular}{|c|c|c|c|c|c|c|}
\hline & \multicolumn{3}{|l|}{ W1 } & \multicolumn{3}{|l|}{$\mathrm{W} 2$} \\
\hline & $\mathrm{RF}[22]$ & FD [22] & RFEM & $\mathrm{RF}[22]$ & FD [22] & RFEM \\
\hline Static top tension $(\mathrm{kN})$ & 1860 & 1860 & 1864 & 1860 & 1860 & 1864 \\
\hline Max tension $(\mathrm{kN})$ & 1895 & 1894 & 1893 & 2193 & 2261 & 2269 \\
\hline Min tension $(\mathrm{kN})$ & 1825 & 1825 & 1817 & 1542 & 1451 & 1446 \\
\hline Max bending moment $(\mathrm{kNm})$ & 542 & 517 & 507 & 575 & 555 & 530 \\
\hline Min bending moment $(\mathrm{kNm})$ & 428 & 401 & 399 & 406 & 375 & 368 \\
\hline
\end{tabular}

Fig. 3 Comparative analysis for static equilibrium: a configuration of the riser, $\mathbf{b}$ tension force, c bending moment, $\mathbf{d}$ shear force

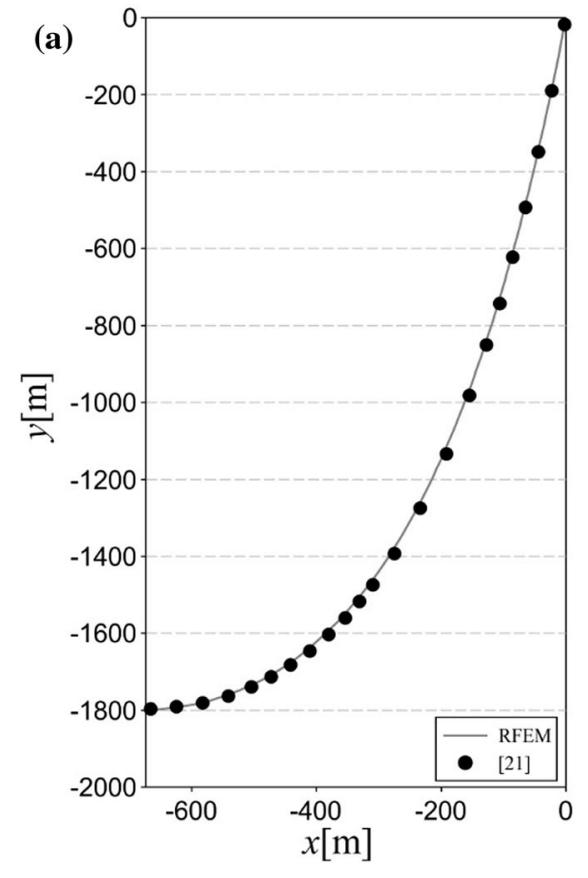

(b)

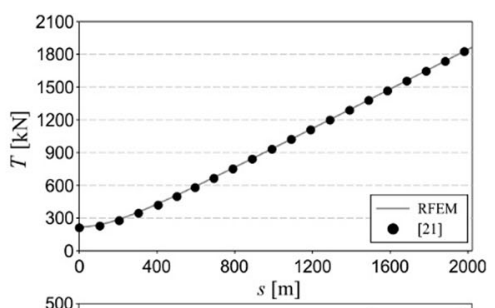

(c)

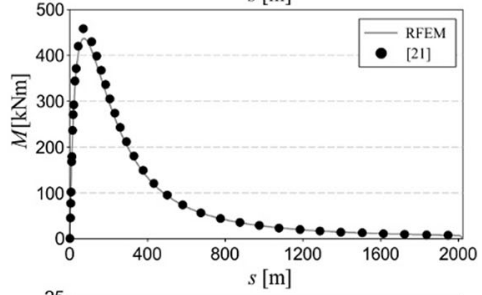

(d)

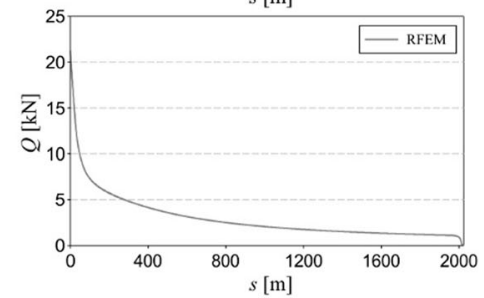

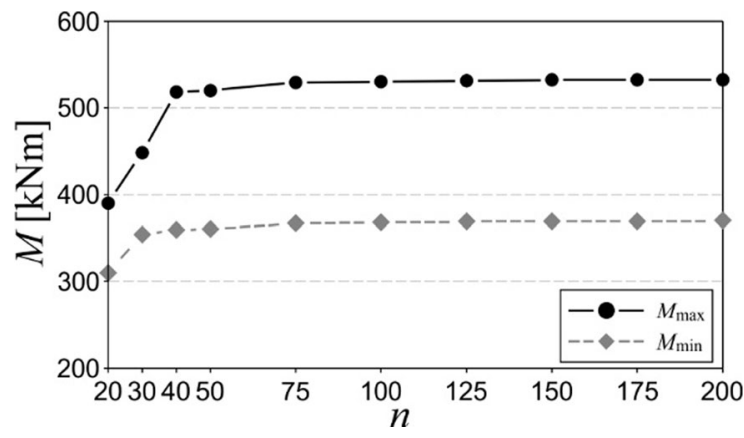

Fig. 4 Maximal and minimal values of the bending moment at selected points (W2)

The task is solved by definition of the rotation angle of a hoisting winch, which is responsible for keeping the load at a set distance from the seabed.
For the purpose of this paper the optimisation task is formulated as follows (Fig. 5).

The horizontal motion of a vessel (platform) is defined by (6). Such movements cause a significant increase in bending moments in the riser presented in Fig. 2, which finally can lead to damage of the structure. This means that the problem is very important from the practical point of view. Thus, the vertical motion of point $E$ (the upper end of the riser) should be chosen in such a way that the bending moment at a given point of the riser is as close as possible to the static bending moment. For further analysis it is assumed that the riser parameters are the same as those presented in Table 1. The course of the bending moment calculated at given points for $a=3 \mathrm{~m}$ and $T=12 \mathrm{~s}$ in formula (6) is presented in Fig. 6. 


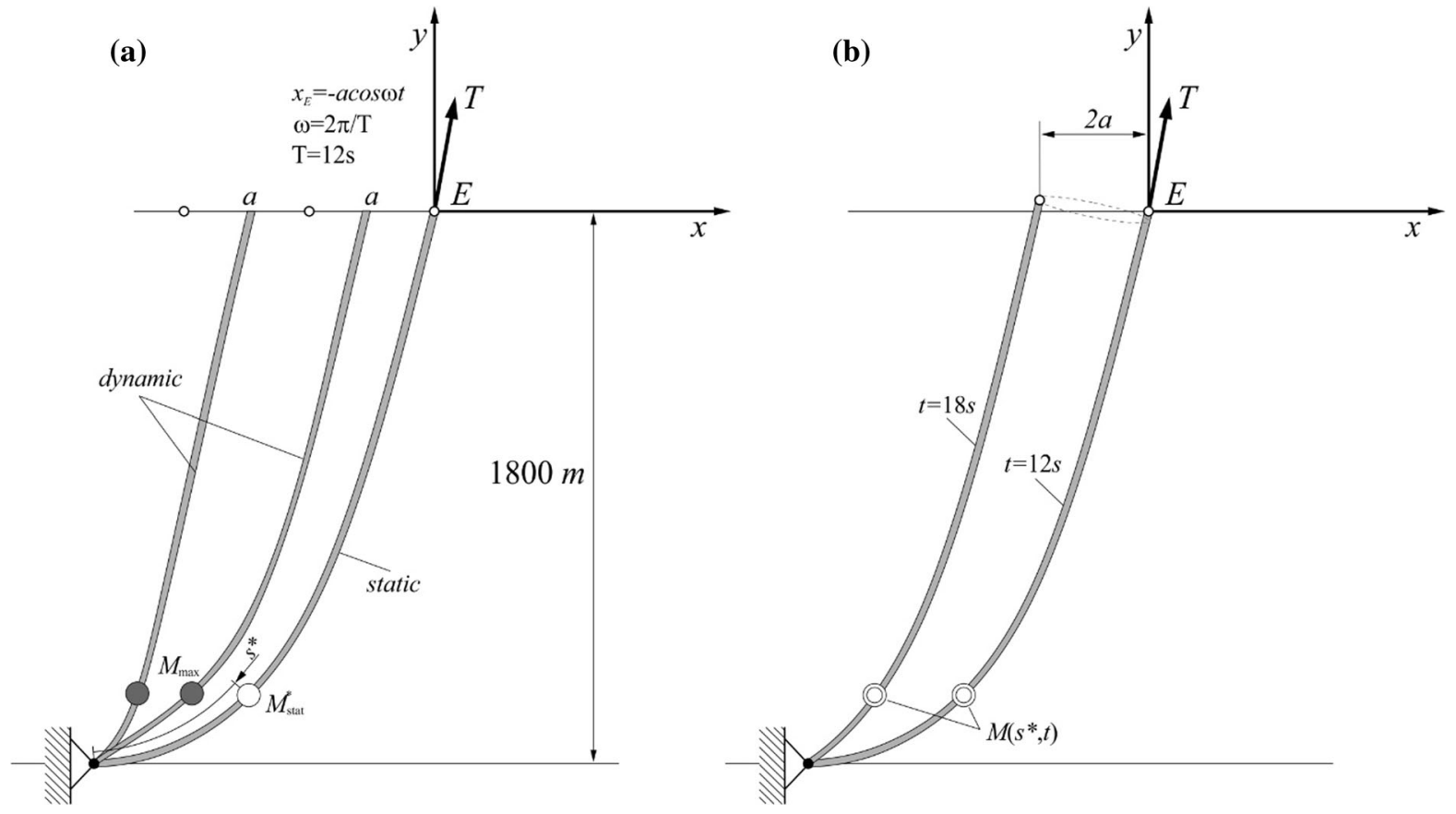

Fig. 5 Riser configuration during optimisation: a without compensation, b with compensation

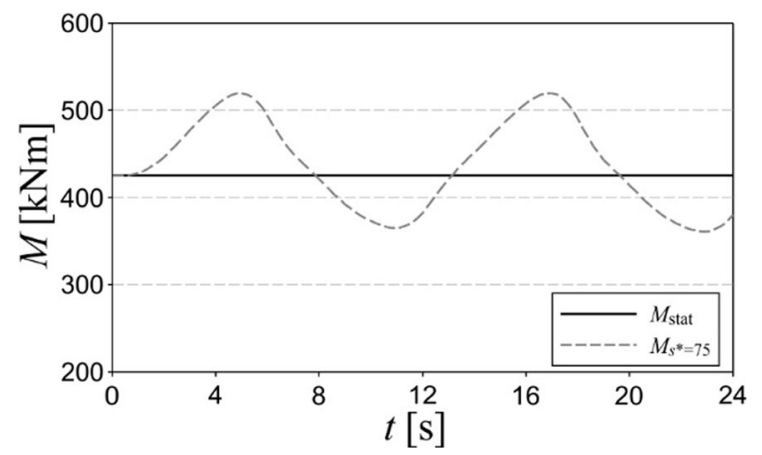

Fig. 6 Courses of the bending moment at selected points

Courses of minimal and maximal values of the bending moment along the riser for the second type of harmonic motion (W2) are presented in Fig. 7.

The optimisation task is formulated using the spline functions of the third order as follows:

Find function $y_{E}(t)$ for $t \in 0, T$ defined by means of parameters:

$$
\left\{\begin{array}{c}
p_{1}=y_{E}\left(t_{1}\right) \\
\vdots \\
p_{i}=y_{E}\left(t_{i}\right) \\
\vdots \\
p_{m}=y_{E}\left(t_{m}\right)
\end{array}\right.
$$

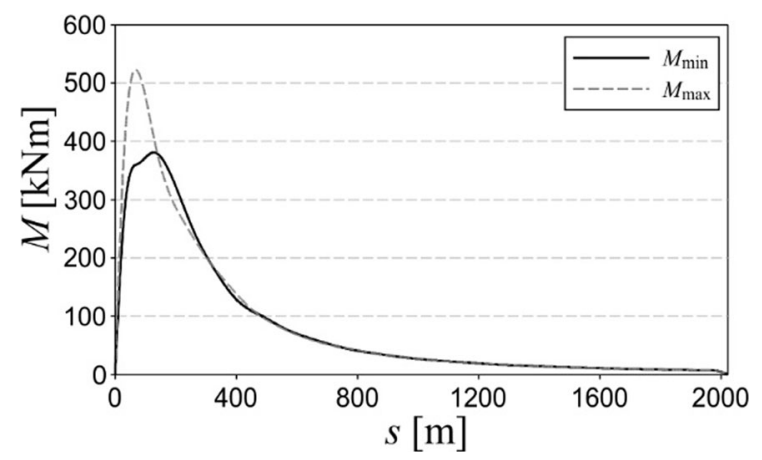

Fig. 7 Course of the maximal and minimal values of the bending moment

where $t_{i}=i \Delta t$ for $i=1,2, \ldots, m, \Delta t=\frac{T}{m}$, so that the function:

$\Omega\left(p_{1}, \ldots, p_{m}\right)=\frac{1}{T} \int_{0}^{t}\left[M\left(s^{*}, t\right)-M_{s t a t}^{*}\right]^{2} d t$

where $M\left(s^{*}, t\right)$ is the bending moment at the selected point of the riser, $M_{\text {stat }} *$ is the value of this moment for the static equilibrium problem, reaches its minimum while fulfilling the following:

$y_{\text {Emin }} \leq p_{i} \leq y_{\operatorname{Emax}}$ 


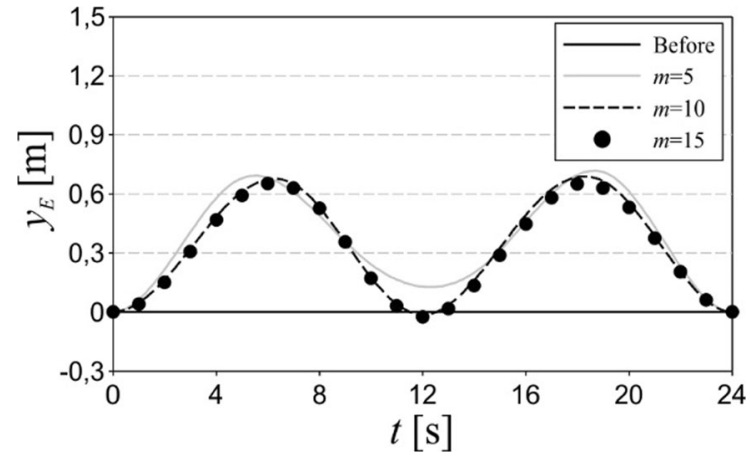

Fig. 8 Courses of function $y_{E}(t)$ with respect to number of time intervals $m$

where $y_{\text {Emin }}, y_{\text {Emax }}$ are minimal and maximal accepted values of function $y_{E}(t)$.In order to calculate the value of functional (8) for a specific combination of parameters $p_{i}(i=1, \ldots, m)$, bending moment $M$ $\left(s^{*}, t\right)$ has to be known. Thus, the equations of motion of the riser have to be integrated at each optimisation step. The downhill simplex method is used for solving the optimisation task.
The parameters occurring in the optimisation problem have to be chosen properly in order to obtain correct results, especially the number of time intervals $m$ in formula (7), and $y_{E \operatorname{Emin}}$ and $y_{\text {Emax }}$ in inequalities (9). A large number of decisive variables $m$ significantly increases simulation time, but too small a number leads to a limitation of function classes describing vertical displacements of point $E$ of the riser. Figure 8 presents the courses of function $y_{E}(t)$ for $m=5,10,15$.

It can be seen that the difference between values of $y_{E}$ obtained for $m=5$ and 10 is large, while for $m=10$ and 15 it is small. Calculation times were $T^{*}=202 \mathrm{~s}$ for $m=5, T^{*}=1220 \mathrm{~s}$ for $m=10$ and $T^{*}=1825 \mathrm{~s}$ for $m=15$. The calculations were carried out for $s^{*}=75 \mathrm{~m}, y_{\text {Emin }}=1.5 \mathrm{~m}$ and $y_{\text {Emax }}=1.5 \mathrm{~m}$. The simulations did not show that values $y_{E \min }$ and $y_{E \max }$ have a significant influence on the exactness of results obtained. The choice of $y_{\text {Emin }}$ and $y_{\text {Emax }}$ was made on the assumption that they should be proportional to the amplitude of the input motion $a$, but should not exceed $\pm 50 \%$ of this value.
Fig. 9 Courses of: a moment $M\left(s^{*}, t\right)$, b top tension $T(L, t)$ before and after the optimisation, c function $y_{E}(t)$
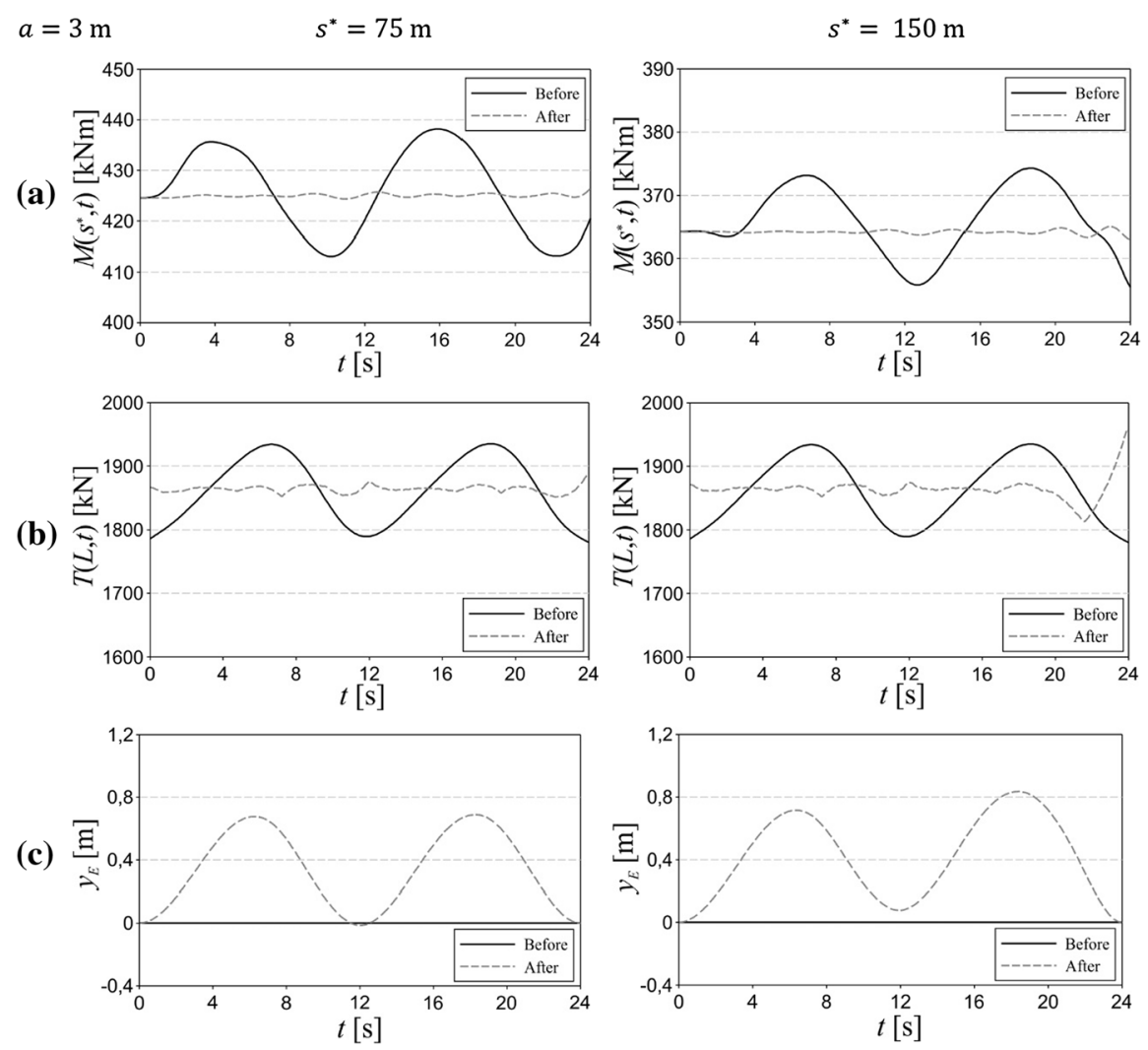
Fig. 10 Courses of: a moment $M\left(s^{*}, t\right)$, b top tension $T(L, t)$ before and after the optimisation, c function $y_{E}(t)$ (a)
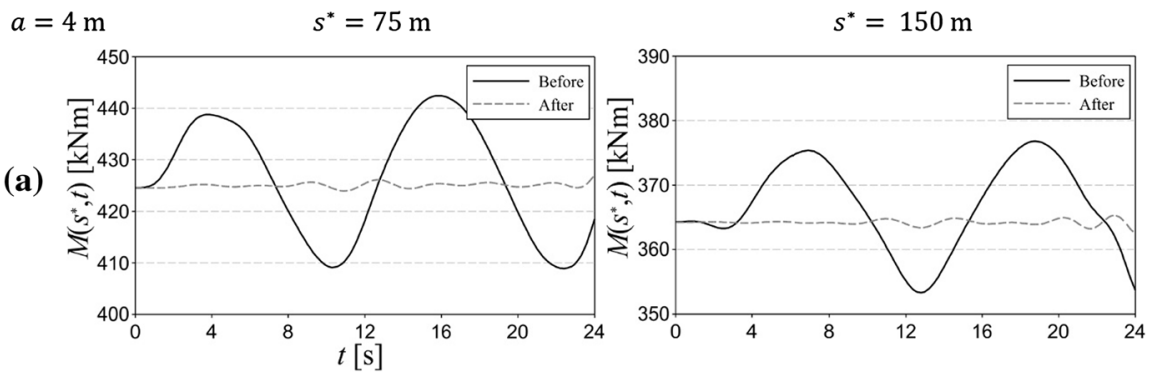

(b)
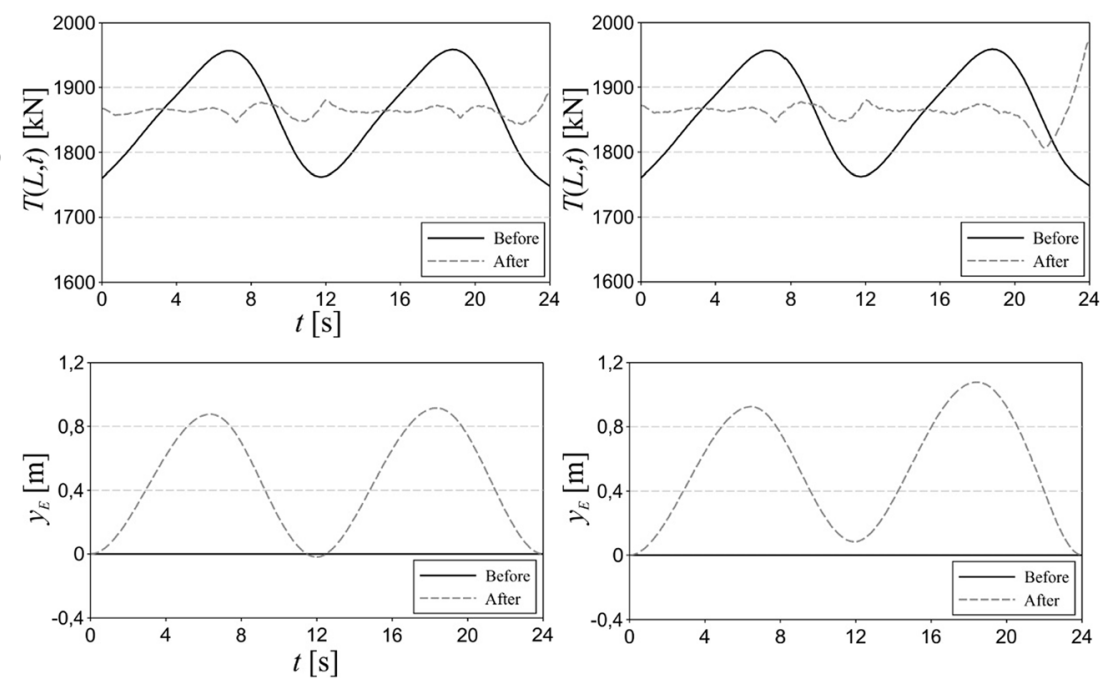

Figures 9, 10 and 11 present the results of optimisation for $a=3,4,5 \mathrm{~m}$. It can be seen that, by means of technically possible vertical motion of the upper end of the riser, the bending moment at any selected point of the riser can be stabilized despite the horizontal movements of the base (vessel or platform). The numerical simulations were carried out for $s^{*}=75,150 \mathrm{~m}$, and the number of discretization points of function $y_{E}(t) m=10$.

It can be seen that the reduction of maximal values of bending moments down to the value of $M_{\text {stat }}^{*}$ at a selected point of the riser is correctly realised. As a result of the optimisation task, the courses of the bending moments are close to the values of bending moment at initial time $t=0 \mathrm{~s}$. Table 3 presents maximal and minimal values of the bending moments and top tension force before and after optimisation.

Reduction of the bending moment at a chosen point and top tension of the riser was achieved by the use of function (8) for the optimisation task. The difference between the maximal and minimal values of the bending moment on average was about $25 \mathrm{kNm}$ and after optimisation this difference was $<10 \mathrm{kNm}$.
Realizing optimal displacements $y_{E}(t)$ involves applying the appropriate top tension at point $E$ of the riser. From Figs. 9b, 10b and $11 \mathrm{~b}$ it can be seen that realization of displacements of point $E$ requires a characteristic force which is not larger than $\pm 5 \%$ of the tangential force. Special devices are necessary for technical realization of the optimal displacement ( $y_{E}(t)$ or force $T(L, t)$ ) Information about the method of realizing displacements at point $E$ and about devices used can be found in papers dealing with "heave compensation systems" [26, 27].

\section{Final remarks}

The paper presents an application of the modification of the rigid finite element method to modeling of dynamics of ropes and risers. The basic advantage of the method is its simple physical interpretation. A flexible link is divided into rigid segments which represent mass features of the link and springdamping elements responsible for its flexible and damping features. The essential aspect of the method 
Fig. 11 Courses of: a moment $M\left(s^{*}, t\right)$, b top tension $T(L, t)$ before and after the optimisation, c function $y_{E}(t)$ (a)
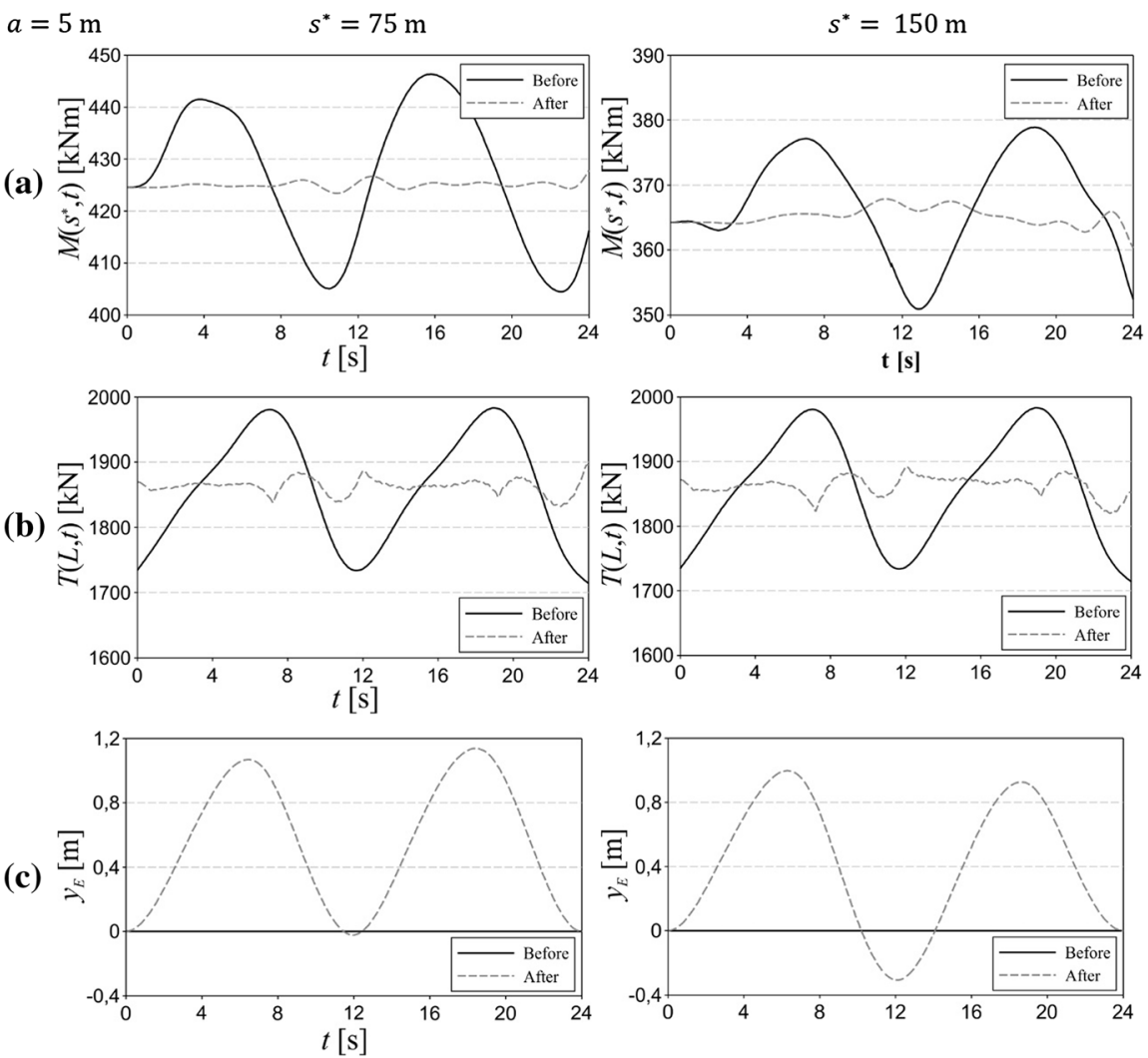

Table 3 Maximum and minimum of values of the bending moment and top tension before and after optimisation

\begin{tabular}{|c|c|c|c|c|c|c|c|c|c|c|c|c|}
\hline \multirow{3}{*}{$\begin{array}{l}a(\mathrm{~m}) \\
s^{*}(\mathrm{~m}) \\
\text { Optimisation }\end{array}$} & \multicolumn{4}{|l|}{3} & \multicolumn{4}{|l|}{4} & \multicolumn{4}{|l|}{5} \\
\hline & \multicolumn{2}{|l|}{75} & \multicolumn{2}{|l|}{150} & \multicolumn{2}{|l|}{75} & \multicolumn{2}{|l|}{150} & \multicolumn{2}{|l|}{75} & \multicolumn{2}{|l|}{150} \\
\hline & B & A & B & A & B & A & B & A & B & A & B & A \\
\hline$M_{\max }(\mathrm{kNm})$ & 438 & 426 & 374 & 365 & 442 & 427 & 377 & 365 & 446 & 428 & 379 & 368 \\
\hline$M_{\min }(\mathrm{kNm})$ & 413 & 424 & 355 & 363 & 409 & 424 & 353 & 363 & 404 & 423 & 351 & 360 \\
\hline$T_{\max }(\mathrm{kN})$ & 1940 & 1885 & 1940 & 1955 & 1962 & 1890 & 1962 & 1969 & 1989 & 1896 & 1989 & 1892 \\
\hline$T_{\min }(\mathrm{kN})$ & 1785 & 1851 & 1785 & 1813 & 1757 & 1843 & 1757 & 1805 & 1726 & 1831 & 1726 & 1819 \\
\hline
\end{tabular}

$B$ before, $A$ after

is the possibility of accounting for large deflections of links. The formulation using absolute coordinates gives reliable results both in the range of static and dynamic analysis. The static analysis concerned with a catenary line shows that the largest differences obtained using the RFEM are less than $0.5 \%$ in comparison to the analytically calculated values of deflections. Free vibrations can be also calculated using the method without the necessity of special formulations. The results obtained using the modified rigid finite element method are compared with those presented by other authors and obtained using commercial software, and very good compatibility is obtained. Thus the models and programs formulated are reliable and numerically efficient. Calculation time is considerably shorter than that necessary for simulations by means of commercial software. The simple physical interpretation and the numerical efficiency of the method enables the method to be applied in engineering design of 
offshore equipment, especially in dynamic analysis of flexible structures, dynamic optimization problems and control. An exemplary optimisation problem is presented and solved in the paper. However, the problem can be generalized by including several points along the riser in the functional $\Omega$. Since the method enables us to calculate forces in the connections of the elements (as constraint reactions) it is possible to formulate tasks in which the limitations are imposed not only on the bending moment but also longitudinal or transversal forces. Solution of several optimisation tasks (for example for different parameters of waves, length of risers) can be used for training an artificial neural network, which then can be used in control.

Open Access This article is distributed under the terms of the Creative Commons Attribution 4.0 International License (http://creativecommons.org/licenses/by/4.0/), which permits unrestricted use, distribution, and reproduction in any medium, provided you give appropriate credit to the original author(s) and the source, provide a link to the Creative Commons license, and indicate if changes were made.

\section{References}

1. Benedettini F, Rega G, Vestroni F (1986) Modal coupling in the free nonplanar finite motion of an elastic cable. Meccanica 21:38-46

2. Benedettini F, Rega G, Alaggio R (1995) Non-linear oscillations of a four-degree-of-freedom model of a suspended cable under multiple internal resonance conditions. J Sound Vib 182(5):775-798

3. Rega G, Alaggio R, Benedettini F (1997) Experimental investigation of the nonlinear response of a hanging cable. Part I: local analysis. Nonlinear Dyn 14:89-117

4. Benedettini F, Rega G (1997) Experimental investigation of the nonlinear response of a hanging cable. Part I: global analysis. Nonlinear Dyn 14:119-138

5. Chakrabarti S (2008) Challenges for a total system analysis on deepwater floating systems. Open Mech J 2:28-46

6. Patel MH, Seyed FB (1995) Review of flexible riser modelling analysis techniques. Eng Struct 17(4):293-304

7. Raman-Nair W, Baddour R (2003) Three-dimensional dynamics of a flexible marine riser undergoing large elastic deformations. Multibody Syst Dyn 10:393-423

8. Liping S, Bo Q (2011) Global analysis of a flexible riser. J Mar Sci Appl 10:478-484

9. Kaewunruen S, Chiravatchradej J, Chucheepsakul S (2005) Nonlinear free vibrations of marine risers/pipes transporting fluid. Ocean Eng 32:417-440

10. Park H-I, Jung D-H (2002) A finite element method for dynamic analysis of long slender marine structures under combined parametric and forcing excitations. Ocean Eng 29:1313-1325

11. Chai YT, Varyani KS (2006) An absolute coordinate formulation for three-dimensional flexible pipe analysis. Ocean Eng 33:23-58

12. Xu X, Wang S (2012) A flexible-segment-model-based dynamics calculation method for free hanging marine risers in re-entry. China Ocean Eng 26:139-152

13. Jensen GA, Säfström N, Nguyen TD, Fossen TF (2000) A nonlinear PDE formulation for offshore vessel pipeline installation. Ocean Eng 37:365-377

14. Niedzwecki JM, Liegre P-YF (2003) System identification of distributed-parameter marine riser models. Ocean Eng 33:1387-1415

15. Chen H, Xu S, Guo H (2011) Nonlinear analysis of flexible and steel catenary risers with internal flow and seabed interaction effects. J Mar Sci Appl 10:156-162

16. Wittbrodt E, Adamiec-Wójcik I, Wojciech S (2006) Dynamics of flexible multibody systems: rigid finite element method. Springer, Berlin

17. Wittbrodt E, Szczotka M, Maczyński A, Wojciech S (2012) Rigid finite element method in analysis of dynamics of offshore structures. Springer, Berlin

18. Adamiec-Wójcik I, Nowak A, Wojciech S (2011) Comparison of methods for vibration analysis of electrostatic precipitators. Acta Mech Sin 27:72-79

19. Adamiec-Wójcik I, Awrejcewicz J, Nowak A, Wojciech S (2014) Vibration analysis of collecting electrodes by means of the hybrid finite element method. Math Probl Eng. doi:10.1155/2014/832918

20. Adamiec-Wójcik I, Awrejcewicz J, Brzozowska L, Drąg Ł (2014) Modeling of ropes with consideration of large deformations by means of the rigid finite element method. Appl Non-linear Dyn Syst Springer Proc Math Stat 93:115-137

21. Adamiec-Wójcik I, Brzozowska L, Drąg $Ł$ (2015) An analysis of dynamics of risers during vessel motion by means of the rigid finite element method. Ocean Eng 106:102-114

22. Chatjigeorgiou IK (2008) A finite difference formulation for the linear and nonlinear dynamics of $2 \mathrm{D}$ catenary risers. Ocean Eng 35:616-636

23. Sorokin SV, Rega G (2007) On modelling and linear vibrations of arbitrarily sagged inclined cables in a quiescent viscous fluid. J Fluid Struct 23:1077-1092

24. Drạg $Ł$ (2016) Model of an artificial neural network for optimization of payload positioning in sea waves. Ocean Eng 115:123-134

25. Drag $Ł$ (2016) Application of dynamic optimisation to the trajectory of a cable suspended load. Nonlinear Dyn. doi: 10.1007/s11071-015-2593-0

26. Rustad AM, Larsen CM, Sorensen AJ (2008) FEM modelling and automatic control for collision prevention of top tensioned raisers. Mar Struct 21:80-112

27. Do KD, Pan J (2008) Nonlinear control of an active heave compensation system. Ocean Eng 35:558-571 